\section{Transplante de fígado e alocação dos órgãos no Brasil: entre Rawls e o utilitarismo}

\author{
Liver transplants and organ allocation in Brazil: \\ from Rawls to utilitarianism
}

Trasplante de hígado y asignación de órganos en

Brasil: entre Rawls y el utilitarismo

\section{Resumo}

O processo de doação e transplante hepático no Brasil revela grandes desigualdades entre regiões e Unidades da Federação, desde a captação de órgãos até o implante do fígado. Em 2006, o escore MELD (Model for End-stage Liver Disease), inspirado no modelo estadunidense e baseado no princípio da necessidade, foi introduzido no Brasil para a alocação de fígado. Porém, as desigualdades no nosso país têm comprometido, parcialmente, o sucesso dessa iniciativa. Em outros países, já se presencia uma crescente discussão sobre $o$ benefício de modelos que tentam harmonizar utilitarismo e necessidade. $O$ presente artigo revisa a literatura pertinente com um foco especial na realidade brasileira.

Transplante de Fígado; Obtenção de Tecidos e Órgãos; Política de Saúde
Edison Moraes Rodrigues-Filho 1

Cristiano Augusto Franke 2

José Roque Junges 1

doi: 10.1590/0102-311X00155817

\author{
Correspondência \\ E. M. Rodrigues-Filho \\ Rua da Gávea 64/3, Porto Alegre, RS 91760-040, Brasil. \\ 1 Universidade do Vale do Rio dos Sinos, São Leopoldo, Brasil. \\ 2 Hospital de Clínicas de Porto Alegre, Porto Alegre, Brasil.
}




\section{Introdução}

A alocação de órgãos para transplantes segue dois princípios filosóficos aparentemente inconciliáveis: a justiça distributiva, conforme Rawls 1, baseada no critério da maior necessidade como prioridade, e o utilitarismo, baseado no critério da maior utilidade do procedimento. Enquanto a necessidade considera a gravidade do doente em lista de espera, a utilidade considera os anos de vida potencialmente ganhos com o procedimento para um determinado paciente, a despeito da gravidade dele. Alguns modelos de alocação de órgãos tentam harmonizar justiça rawlsiana e utilitarismo.

O presente artigo revisa a alocação de órgãos para transplante de fígado no mundo e no Brasil, especialmente após a introdução do escore Model for End-stage Liver Disease (MELD) como forma de alocação por gravidade, sob o prisma da discussão entre a teoria da justiça de Rawls e o utilitarismo. São salientadas as desigualdades do país e possíveis distorções geradas ou perpetuadas após a introdução do MELD. São levantadas questões e propostas sugestões sobre o papel da justiça distributiva dentro de um sistema de saúde que busca primar pela universalidade e equidade. A desigualdade existente no Brasil em relação à distribuição de equipes transplantadoras e à obtenção de órgãos para transplante é uma questão importante em saúde pública.

\section{Os princípios envolvidos na alocação de órgãos}

A alocação de órgãos sofre uma influência significativa do critério da utilidade, o que reflete a força do utilitarismo como filosofia política nos últimos dois séculos. O utilitarismo ainda é muito atraente, pois fornece uma ferramenta de fácil aplicação para decisões políticas, como a alocação de órgãos. Originário das ideias de Jeremy Bentham e John Stuart Mill, aplica, ao nível social, um conceito individual de felicidade. Esse conceito individual de felicidade assevera que a maior ou menor felicidade de uma vida é resultante da diferença entre a soma de momentos felizes e da soma de momentos não felizes. O utilitarismo transpõe esse conceito para a sociedade, de forma que as decisões políticas devem atingir o maior grau de felicidade para o maior número possível de indivíduos, a despeito da forma como essa felicidade se distribui entre os indivíduos 2. Embora de aparente simplicidade, pode permitir uma série de paradoxos, como uma parcela da sociedade sob níveis de infelicidade considerados intoleravelmente injustos para um estado liberal e democrático. Modelos utilitaristas consideram, como melhor candidato para transplante, o paciente que pode ganhar o maior número de anos de vida por procedimento. Dessa forma, esses modelos calculam o benefício real em sobrevida obtido pelo transplante com uma fórmula que considera o número de anos ganhos menos o número de anos oferecidos por tratamentos alternativos 3 .

Por outro lado, a alocação conforme a gravidade dos receptores em lista de espera é uma aplicação da concepção de justiça distributiva e do princípio da diferença de John Rawls 1. A justiça distributiva, conforme Rawls, privilegia a equidade na distribuição de bens e recursos considerados comuns, numa tentativa de igualar as oportunidades de acesso a esses bens, utilizando a necessidade como critério de justiça para dar "a cada um o que é seu" 4.

Em seu livro Uma Teoria da Justiça 1, publicado originalmente em 1971, Rawls desenvolveu uma concepção geral de justiça com a ideia central de que todos os bens primários de uma sociedade (liberdade e oportunidade, renda e riqueza, e as bases do respeito de si mesmo) devem ser distribuídos igualmente, a menos que uma distribuição desigual de qualquer um ou de todos esses bens seja vantajosa para os menos favorecidos. Dessa forma, as desigualdades são permitidas se aumentarem as parcelas inicialmente iguais de todos, mas não são permitidas se, como no utilitarismo, puderem reduzir as menores parcelas inicialmente equitativas de alguns 1,5 .

Os princípios da teoria da justiça desenvolvida por Rawls são os seguintes: (1) cada pessoa deve ter direito igual ao sistema total mais extenso de liberdades básicas compatíveis com um sistema de liberdades similar para todos; (2) as desigualdades sociais e econômicas devem ser ordenadas de modo que sejam: (a) para o maior benefício dos que têm menos vantagens (princípio da diferença); e (b) vinculadas a cargos e posições abertos a todos sob condições de igualdade de oportunidades equitativas (princípio da igualdade justa de oportunidades). 
As liberdades que constituem o primeiro princípio são os direitos civis e políticos básicos reconhecidos nas democracias liberais, ou seja, o direito de votar, o direito de concorrer a cargos públicos, de ter um devido processo com amplo direito de defesa sem prisões arbitrárias, liberdade de expressão política, liberdade de culto religioso ou de não possuir religião, direito de livre circulação etc. 1,5.

O princípio da diferença é prioritário em relação à igualdade justa de oportunidades, visando estabelecer um sistema social ideal, em que aqueles arbitrariamente "sorteados" pelas circunstâncias sociais ou talentos naturais recompensem os demais. No princípio da diferença, todas as desigualdades devem operar de forma a beneficiar os menos favorecidos 1,5. A filosofia de Rawls se insere na tradição do contrato social, especialmente de Locke, Rousseau e sobretudo Kant. Esses autores, assim como Hobbes, considerado o precursor da ideia de contrato social, diferenciam-se pelas razões que induziriam os indivíduos ao acordo e pelos processos elaborados para se atingir o consenso 6 . A influência de Kant é evidente, fazendo da teoria da justiça de Rawls uma teoria deontológica, pois o que importa é o correto a se fazer e não o que é bom fazer. O oposto é justamente uma teoria "teleológica", rejeitada porque oferece fundamentos frágeis para os direitos e liberdades, cujas violações podem ser justificadas em nome de um determinado objetivo ${ }^{7}$. Apesar da inspiração kantiana, Rawls defende que a sua teoria se baseia em um ideal, e não em deveres, como no pensamento de Kant 8.

Como no fundo da reflexão de Rawls de uma sociedade bem ordenada há a premissa de que esse ordenamento surgiria de um acordo entre homens livres, racionais, interessados no próprio bem-estar e responsáveis pelas vantagens da cooperação, o autor propôs um exercício teórico partindo de uma "posição original" sob um "véu de ignorância" 1 . O "véu de ignorância" tem um caráter procedimental para garantir a imparcialidade do processo e a equidade do resultado. Dessa forma, os indivíduos envolvidos no processo decisório se orientariam pela ideia de minimizar as desvantagens, e não pela maximização do bem ou pelo utilitarismo 6 .

A filosofia política de Rawls depende de alguns pressupostos hipotéticos para atingir seus três princípios. O primeiro pressuposto é a posição original, na qual os contratantes desconhecem sua posição social, formação intelectual e aptidões físicas. O segundo pressuposto é que, nessa condição, a escolha racional seria por uma sociedade em que a pior alternativa escolhida seria a melhor possível, conhecida como a maximização do mínimo ou maximin. O terceiro pressuposto é que as sociedades seriam estáveis, e uma vez escolhendo-se um determinado arranjo, ele seria irreversível 9.

A teoria da justiça de Rawls é uma teoria padronizada da justiça. Teorias padronizadas afirmam "a cada um conforme...". No caso da teoria de Rawls, a cada um conforme a sua necessidade. Outras versões de teorias padronizadas distribuiriam bens conforme outros critérios, como mérito, posição social, obras realizadas pelo beneficiado ou o que a lei definir, todas frágeis em relação à saúde. Teorias não padronizadas, por sua vez, baseiam-se, unicamente, na legitimidade da aquisição de determinados bens 9 .

Alguns autores têm proposto escores que procuram equilibrar o risco de óbito na lista de espera com os anos de vida ganhos com o transplante, procurando harmonizar a justiça de Rawls com o utilitarismo 10,11. Em parte, isso reflete a simpatia de muitos transplantadores com a ótica utilitarista, o que pode influenciar, implícita ou explicitamente, as decisões tomadas por esses profissionais, mesmo em sistemas de saúde orientados pela necessidade. Isso ocorre porque muitas equipes de transplante de fígado buscam otimizar seus resultados no início das suas atividades, podendo selecionar doentes com maior chance de sobrevida pós-transplante em detrimento dos doentes mais graves 11 .

Os transplantes de órgãos e tecidos são um retrato do avanço tecnocientífico do século XX. O primeiro transplante hepático foi realizado em 1963 por Thomas Starzl, e o primeiro transplante com sobrevida ao procedimento também foi realizado por Starzl, em 1967 12. No entanto, por muitos anos, o transplante hepático persistiu como um procedimento quase experimental até que um consenso, promovido pelo U.S. National Institutes of Health, em 1983, definiu esse tratamento como indicado para diversas doenças hepáticas em estágio final de evolução ${ }^{13}$. Desde então, o transplante de fígado se tornou o tratamento mais efetivo para diversas indicações 14,15 . 


\section{A alocação de fígados para transplante no mundo}

A primeira iniciativa estadunidense para regular a alocação de órgãos ocorreu em 1984 quando o Congresso daquele país criou a OPTN (Organ Procurement and Transplantation Network). Essa rede monitora todos os pacientes listados para transplantes de órgãos e é responsável pela procura, alocação e transplante de órgãos sólidos em todo o país. Existem, aproximadamente, 140 centros transplantadores de fígado nos Estados Unidos, e cada centro é membro de uma OPO (Organ Procurement Organization) local, entre as 62 OPOs espalhadas pelo país. A política de alocação estabelece que, em geral, o fígado doado é alocado para o doente com o MELD mais elevado dentro da área de abrangência da respectiva OPO. A exceção mais importante são os raros casos de insuficiência hepática aguda, considerados como prioritários por outros critérios de gravidade, que não o MELD. Antes de 1997, a prioridade também era definida pela gravidade, porém baseada no status hospitalar (internados em unidade de terapia intensiva, internados em unidades hospitalares que não a terapia intensiva e doentes ambulatoriais em ordem decrescente de prioridade; e, dentro de cada um desses três grupos, conforme o tempo em lista de espera). Devido à imperfeição do “critério hospitalar", em 1997, apenas o tempo de espera em lista passou a ser utilizado. Porém, um efeito inadvertido dessa mudança foi a prática de inclusão "precoce" de doentes na lista de espera, para que eles pudessem contabilizar o tempo antes de uma piora clínica que pudesse inviabilizar o transplante. Assim, em 1998, passou-se a utilizar o escore Child-Turcotte-Pugh (CTP) que combina parâmetros clínicos e bioquímicos em um escore global de A, B ou C com progressão da gravidade de doença de A a C. Ainda que tenha representado um avanço na UNOS (United Network for Organ Sharing), essa forma permaneceu imperfeita, pois muitos fatores utilizados para a classificação do CTP são clinicamente subjetivos. Em função disso, o U.S. Department of Health and Human Services interveio em 1998 e desafiou a comunidade transplantadora a criar a chamada "Final Rule" (Regra Final) visando assegurar que os fígados doados fossem alocados por critérios médicos objetivos, e não resultantes de aspectos subjetivos ou fruto de um acidente geográfico, esse último resultante de discrepâncias geográficas existentes nos Estados Unidos em função da diferença de abrangência das diferentes OPOs 16. Dessa forma, após um longo debate, o escore MELD, que determina a gravidade da doença hepática e estima o risco de óbito na lista de espera, foi implantado, em fevereiro de 2002, para alocação dos fígados doados aos doentes com maior prioridade 17 .

Após a introdução do MELD nos Estados Unidos, foram observados um maior número de pacientes transplantados mais gravemente doentes e uma redução da mortalidade na lista de espera sem afetar a sobrevida de pacientes e enxertos no primeiro ano pós-transplante, pois algumas discrepâncias geográficas persistiram nos Estados Unidos, já que certas regiões transplantam pacientes com MELD em torno de 23 (incluindo estados como Kentucky e Tennessee), e outras transplantam pacientes com MELD superior a 30 (incluindo estados como Nova York e Califórnia) 16. O risco de óbito superior nessas últimas regiões levou a UNOS a considerar uma nova proposta de distribuição dos fígados em uma área geográfica tão ampla quanto viável, de forma a reduzir a variabilidade entre os programas de transplante, iniciativa que tem sido um foco de controvérsia permanente nos Estados Unidos 18,19

O escore MELD foi, inicialmente, desenvolvido para predizer a mortalidade de pacientes submetidos ao procedimento de introdução percutânea de TIPS (Transjugular intrahepatic portosystemic shunt), uma prótese minimamente invasiva que visa aliviar a hipertensão portal desses doentes, responsável por episódios de hemorragia digestiva potencialmente fatais. Somente algum tempo depois, também se demonstrou que o MELD era um excelente método para predição de mortalidade entre 3 e 12 meses para os doentes cirróticos, o que levou a sua utilização como mecanismo de priorização dos doentes mais graves para transplante de fígado. A fórmula do MELD utiliza bilirrubina, INR (International Normalized Ratio) e creatinina como variáveis, todos dados laboratoriais objetivos e facilmente disponíveis 20. A utilização do MELD é inspirada na justiça distributiva, ou seja, "a cada um conforme a sua necessidade".

Por outro lado, considerando uma lógica de alocação utilitarista, Dutkowski et al. 21 relataram um estudo com a validação de um novo escore para a alocação dos fígados, o Balance of Risk Score (escore BAR), em uma pequena população suíça (233), porém derivado do banco de dados da UNOS estadunidense. Além do valor do MELD dos candidatos, esse escore também incorpora o tempo de isquemia fria, a idade do receptor, a idade do doador, o fato de se tratar ou não de um retransplante hepático e 
a dependência de suporte vital (ventilação mecânica ou suporte bioartificial) prévia ao transplante. O novo escore foi descrito como potencialmente superior ao MELD como método de priorização dos doentes para a alocação de órgãos 21 . No entanto, neste estudo, o MELD dos candidatos com hepatocarcinoma não foi tratado de forma especial com imputação de pontos adicionais, como é feito na maioria dos países que utilizam esse escore, o que pode ter superestimado o seu potencial benefício.

$\mathrm{Na}$ Europa centro-ocidental, por exemplo, das seis principais macrorregiões ou países - Centro Nazionale Trapianti na Itália; Eurotransplant (Alemanha, Holanda, Bélgica, Luxemburgo, Áustria, Hungria, Eslovênia e Croácia); Organización Nacional de Trasplantes na Espanha; Agence Nationale de la Biomédecine na França; NHS Blood \& Transplant no Reino Unido e Irlanda; e Scandiatransplant (Suécia, Noruega, Finlândia, Dinamarca, e Islândia) -, apenas a Scandiatransplant não utiliza o MELD ou alguma versão customizada do MELD. Deve-se ressaltar que, na área de abrangência da Scandiatransplant, ocorre uma relação extremamente favorável entre demanda e oferta de fígados para transplante, minimizando o potencial benefício da alocação por gravidade, já que existem fígados para todos receptores listados em tempo hábil 1.

\section{A alocação de fígados para transplante em adultos no Brasil e o impacto do MELD}

No Brasil, o Registro Brasileiro de Transplantes (RBT) de 2016, efetuado pela Associação Brasileira de Transplantes de Órgãos (ABTO), registrou uma necessidade estimada de 5.111 transplantes hepáticos, dos quais, 1.880 foram realizados 22 . Apesar dessa necessidade estimada, em dezembro de 2016, haviam somente 1.331 doentes adultos "ativos" em lista de espera. Em 2016, ingressaram 3.733 novos doentes adultos, e foram registrados 723 óbitos em lista de espera adulta para transplante hepático. Das 27 Unidades da Federação (26 estados e o Distrito Federal), 11 não registraram nenhuma inclusão em lista de espera para transplante hepático adulto, a maioria por não possuírem equipes transplantadoras, o que faz com que os doentes desses estados precisem ser listados em outras Unidades da Federação. No país, existem 62 equipes concentradas em 12 estados e no Distrito Federal, um número relativamente estabilizado nos últimos quatro anos. O número de transplantes hepáticos vem apresentando um crescimento discreto ao longo dos anos, que, em 2016, deveu-se, basicamente, a um aumento no número de doadores vivos. A distribuição de transplantes hepáticos realizados por milhão de habitantes em 2016, por grandes regiões, revela o seguinte: Região Sul (17,6pmp), Região Sudeste (10,9pmp), Região Nordeste (6,2pmp), Região Centro-oeste (4,9pmp) e Região Norte (0,4pmp) 22. Portanto, mais de $70 \%$ dos transplantes hepáticos são realizados nas regiões Sul e Sudeste, onde se distribuem pouco mais de $55 \%$ da população brasileira. É importante salientar que, embora o cadastro nacional seja único, a distribuição de órgãos doados por morte encefálica é, inicialmente, estadual e, posteriormente, dentro de macrorregiões estabelecidas na Portaria no 2.600 do Ministério da Saúde, de 21 de outubro de 2009 23. A criação das macrorregiões foi uma modificação da Portaria no $2.600 \mathrm{em}$ relação à Portaria no 1.160 24, visando contornar, parcialmente, as desigualdades entre as Unidades da Federação.

Para estarem "ativos" na lista de espera, ou seja, aptos a concorrerem aos órgãos ofertados, os doentes precisam estar com o MELD atualizado, com periodicidade que varia de sete dias a três meses, conforme o valor do MELD anterior 23. É de responsabilidade da equipe médica transplantadora, a qual o paciente está vinculado, o envio sistemático do resultado dos exames necessários para atualização, conforme a periodicidade estabelecida. Pacientes com MELD desatualizado podem se tornar "semiativos" ou "inativos" e até mesmo serem removidos da lista de espera 23.

Além das disparidades geográficas quanto à disponibilidade de equipes transplantadoras e o possível risco de perda de uma oferta de órgão por não atualização do MELD, também existem disparidades nas diferentes coordenações estaduais em relação à captação de órgãos. As desigualdades geográficas envolvem uma menor incidência de novos casos de morte cerebral, reduzida notificação dos casos de morte encefálica existentes e problemas logísticos comprometendo a captação de órgãos em determinadas regiões, mesmo quando os familiares manifestam ativamente o desejo de doar. Os dados da RBT da ABTO de 2016 mostram que a média de doadores efetivos por milhão de habitantes no Brasil é de 14,6 22. Porém, existem disparidades marcadas entre as diferentes Unidades da Federação. Enquanto o Estado de Santa Catarina obteve 36,8 doadores efetivos, tivemos quatro estados sem nenhum 
doador efetivo por milhão de habitantes no ano de 2016. Paradoxalmente, alguns estados do Sudeste (Rio de Janeiro, Espírito Santo e Minas Gerais), uma região que realiza uma grande parte dos transplantes brasileiros, apresentaram um quantitativo de doadores efetivos abaixo da média nacional 22. É importante salientar que doador efetivo é aquele em que se inicia o procedimento de retirada de órgãos, portanto, não significando, necessariamente, a retirada de fígados e, menos ainda, o implante de fígados retirados, pois os órgãos retirados podem ser descartados por uma série de questões, desde contraindicações posteriores à retirada até problemas de logística.

No Brasil, o MELD foi introduzido em 29 de maio de 2006, por meio da Portaria $n^{\circ} 1.160$ do Ministério da Saúde 24. De 1997 a 2006, a alocação de órgãos de doadores em morte encefálica era baseada, exclusivamente, no critério cronológico, de acordo com a ordem de inclusão em lista de espera 25. Antes da introdução da lista única em 1997, a decisão de quem e quando transplantar ficava exclusivamente a critério das equipes transplantadoras 26.

Convém salientar que a priorização pela gravidade, definida pelo MELD, não é absoluta em relação ao critério cronológico, pois a fórmula que determina a prioridade em lista e define a alocação de um fígado doado no Brasil ainda incorpora, parcialmente, o tempo de lista na pontuação final 23. Além disso, também se leva, em conta, a identidade $\mathrm{ABO}$ dos grupos sanguíneos. São exceções à identidade $\mathrm{ABO}$, aceitando-se apenas a compatibilidade $\mathrm{ABO}$, os receptores do grupo $\mathrm{B}$ que podem concorrer também aos órgãos de doadores do grupo $\mathrm{O}$, e os receptores do grupo $\mathrm{AB}$ que podem concorrer também aos órgãos de doadores do grupo A. Essas exceções se devem ao fato da menor representação dos grupos sanguíneos $\mathrm{B}$ e $\mathrm{AB}$ na população brasileira, portanto, com uma menor possibilidade de receber um órgão com identidade $\mathrm{ABO}$. Porém, a qualquer momento, a compatibilidade $\mathrm{ABO}$ pode substituir a identidade $\mathrm{ABO}$, caso não hajam receptores listados para um determinado grupo sanguíneo 23 .

Algumas situações clínicas foram consideradas especiais desde o início, pois, mesmo não afetando seriamente a função hepática, podem levar rapidamente ao óbito sem elevar o MELD. Essas condições são: alguns tumores raros, polineuropatia amiloidótica familiar, síndrome hepatopulmonar grave, algumas doenças metabólicas, hemangiomatose ou doença policística, deficiência de alfa-1 antitripsina e, principalmente, hepatocarcinoma 23,27. Pacientes com essas condições clínicas recebem 20 pontos adicionais ao entrarem na lista de espera, que são, posteriormente, elevados para 24 e 29 pontos após três e seis meses na lista de espera, respectivamente 26 . Também são exceções os casos de insuficiência hepática aguda, não funcionamento primário do enxerto listado em até sete dias após o transplante inicial, e indivíduos que perderam a função hepática por trauma. Esses têm prioridade absoluta e obedecem a outros critérios de gravidade, que não o MELD 23.

Os órgãos são ofertados no mesmo estado, posteriormente, na mesma macrorregião e, por último, nacionalmente, entre os pacientes ativos em lista conforme: (a) identidade ABO (compatibilidade nas exceções previamente citadas); (b) compatibilidade anatômica (discrepâncias entre o peso do órgão ofertado para o peso total dos receptores podem desencadear complicações pós-operatórias); e (c) gravidade determinada pelo MELD somada a uma parte do tempo em lista 23.

A decisão de introduzir esse escore no Brasil baseou-se na acurácia do MELD para predizer a mortalidade nos países em desenvolvimento, embora sem ter sido testado, à época, em coortes de pacientes listados para transplante hepático no Brasil 25. Dependendo da população em que é aplicado, a mortalidade em pacientes com um dado MELD pode não ser necessariamente a mesma 20 . No entanto, Brandão et al. 28 demonstraram a superioridade do MELD em uma coorte de 271 pacientes brasileiros, quando comparado ao CTP (Child-Turcotte-Pugh) e ao EMERALD (Erasmus Model for Endstage Resistant to therapy All etiology Liver Disease), outros dois escores de predição de óbito em doentes cirróticos.

Monteiro et al. 29 investigaram o impacto do MELD nas taxas de sobrevida em um ano de 852 receptores de transplante hepático adulto em São Paulo, comparando 426 doentes na era pré-MELD (critério cronológico) com 426 doentes na era MELD, sem conseguir demonstrar diferenças estatisticamente significativas. Também observaram um pior prognóstico entre receptores transplantados com MELD mais elevados e uma maior frequência de transplantes por hepatocarcinoma. Não foram disponibilizados dados de sobrevida na lista de espera 29.

Tenório e colaboradores, por sua vez, estudaram a mortalidade na lista de espera em Pernambuco na era pré-MELD (250 doentes) e pós-MELD (266 doentes). Embora o tempo na lista de espera tenha sido reduzido de 487,2 $\pm 384,8$ dias para 183,9 $\pm 157,2$ dias, a sobrevida pós-transplante caiu de $93,2 \%$ 
para $83,4 \%{ }^{30}$. No entanto, o mesmo grupo relatou uma melhora de sobrevida pós-transplante após a introdução do MELD, especialmente em doentes sem hepatocarcinoma e com escore MELD de risco moderado (15 a 20) 31 .

Salvalaggio et al. 32 revisaram o banco de dados do Estado de São Paulo de julho de 2003 a julho de 2009. Dividindo os doentes em transplantados na era pré-MELD (3.974 doentes) e pós-MELD (1.936 doentes), demonstraram uma redução significativa no tempo de espera e na mortalidade em lista após a implementação da mudança na alocação 32 .

Machado e colaboradores também relataram uma redução da mortalidade na lista de espera no Rio Grande do Sul pós-MELD (324 doentes na lista e 130 transplantados e, posteriormente, 221 doentes em lista e 115 transplantados) sem alteração na sobrevida pós-transplante, mesmo com um maior número de transplantes realizados em indivíduos mais doentes 33 .

Pestana e colaboradores compararam os desfechos no Estado de São Paulo na era pré-MELD (julho de 2005 a julho de 2006) e na era do MELD (julho de 2006 a julho de 2010). Depois da implementação do MELD, os registros na lista de espera caíram 39,8\%, os transplantes realizados em doentes com hepatocarcinoma subiram de 2,4\% para 23,7\%, e as mortes na lista de espera passaram de 599 para 359. Embora receptores com MELD elevado apresentassem pior sobrevida pós-transplante, não houve diferença global na sobrevida pós-transplante 34 .

Mattos e colaboradores compararam a sobrevida de doentes listados no Rio Grande do Sul na era pré-MELD (162) e na era MELD (184). A curva de sobrevida de Kaplan-Meier dos doentes listados na era MELD foi estatisticamente superior ao período pré-MELD, e essa diferença se manteve nas estimativas de longo prazo 35 .

A introdução do MELD no Brasil aparentemente reduziu o tempo de espera e a mortalidade em lista. Embora tenha ocorrido um aumento na mortalidade pós-transplante dos indivíduos mais doentes, o aumento na sobrevida pós-transplante dos pacientes com hepatocarcinoma parece ter anulado ou mesmo sobrepujado esse efeito. No entanto, o tempo realçou as desigualdades existentes no país em termos de acesso ao Sistema Único de Saúde (SUS), pois os exames para o MELD precisam ser atualizados periodicamente pelas equipes transplantadoras que se distribuem preferencialmente nos grandes centros, especialmente no Sul e Sudeste. Dessa forma, diversos doentes não têm acesso a equipes transplantadoras ou podem não conseguir atualizar seus dados laboratoriais, tornando-se semiativos, removidos ou inativos na lista de espera, podendo, inclusive, morrer como consequência.

\section{Discussão}

Os dados disponíveis no Brasil, em relação ao processo de doação e transplantes, mostram como as desigualdades nos arranjos institucionais referentes à saúde podem ser resistentes a modificações restritas, mesmo que bem intencionadas, de introduzir critérios de justiça distributiva, baseados na necessidade dos usuários. A exposição inicial sobre o sistema de alocação de órgãos nos Estados Unidos é relevante pela importância do utilitarismo no ethos político daquele país (mesmo adotando o critério da necessidade para a alocação de fígados) e pela influência da literatura estadunidense no mundo e no nosso meio.

A alocação de órgãos para transplantes conforme a gravidade dos receptores em lista de espera é uma aplicação de justiça distributiva e do princípio da diferença conforme Rawls 1. O conceito de justiça na concepção de Rawls está associado às relações indiretas entre grupos sociais ou entre indivíduos e grupos sociais. Privilegia a equidade na distribuição de bens e recursos considerados comuns, numa tentativa de igualar as oportunidades de acesso a esses bens, utilizando a necessidade como critério para dar "a cada um o que é seu" 4.

Como ressaltado por Fortes 36 (p. 31-2), "o critério da necessidade é a orientação dos sistemas de saúde fundamentados na noção da universalidade de acesso. A operacionalização desse conceito ocorreu, pela primeira vez, na Inglaterra, com a criação do National Health Service, após a Segunda Guerra Mundial. Com a Constituição Federal de 1988, também, o Brasil seguiu essa orientação, estruturando a área da saúde pública sob a égide do SUS, que substituiu o sistema anterior, previdenciário, baseado na noção do mérito do trabalho. Atualmente, coexiste um sistema de saúde suplementar baseado nas leis de livre mercado com um sistema público de saúde, o SUS, de orientação universalista e atendimento integral das necessidades de saúde”. 
Se certamente houve um momento no Brasil em que o crescimento exponencial do número de serviços transplantadores, mesmo que concentradamente, beneficiou indivíduos de regiões com menos profissionais, ao pertencerem a uma lista única, dentro da lógica do princípio da diferença e da tolerância a desigualdades que favoreçam os mais desfavorecidos, logo essa vantagem ficou enfraquecida. Poucos indivíduos têm estrutura social e familiar para transplantarem órgãos em outras Unidades da Federação, ou mesmo em outras regiões do Brasil, já que há necessidade de uma proximidade das equipes para os cuidados pré e pós-procedimento. Isso se agravou pela necessidade de atualização de dados clínicos e laboratoriais, necessários para a utilização do MELD. É ainda possível que a prerrogativa das equipes em atualizar o MELD traga um componente subjetivo de avaliação de gravidade com consequências inesperadas sobre a posição dos candidatos na lista de espera.

Cabe salientar que as diferenças marcantes em relação à captação de órgãos de doadores em morte encefálica nas diferentes regiões geográficas e Unidades da Federação podem gerar uma série de paradoxos indesejados pela lógica da justiça distributiva conforme Rawls. Comparando-se diferentes Unidades da Federação, quando houver paridade entre disponibilidade de equipes transplantadoras e captação adequada, doentes menos graves podem receber fígados antes de doentes com maior necessidade, pois a distribuição é regionalizada. Além disso, em determinadas Unidades da Federação com equipes transplantadoras atuantes, porém com baixa captação de órgãos, doentes podem vir a falecer na lista de espera.

A introdução do MELD pode ter gerado e perpetuado injustiças no processo de alocação de fígados para transplante, sob a ótica da teoria padronizada da justiça de Rawls, ou seja, "a cada um conforme a sua necessidade". Assim, outras teorias padronizadas podem acabar sendo utilizadas inadvertidamente com a aplicação de algum outro critério para a alocação de órgãos. Pode se estar utilizando a aplicação do princípio de "dar a cada um conforme seus méritos”, priorizando conforme a responsabilidade pessoal pelo autocuidado, priorizando doentes que "não contribuíram” para a sua doença. O critério da responsabilização pelo autocuidado é altamente discutível para utilização na saúde 37, embora Albertsen 38, por exemplo, considere que a responsabilização individual, no caso do consumo de álcool por hepatopatas, pode ser harmonizada com a justiça distributiva. Dessa forma, indivíduos com consumo ativo de álcool perderiam pontos frente a outros candidatos, uma teoria conhecida como luck egalitarianism 38. Cabe ressaltar que, mesmo na ausência de uma discussão filosófica mais ampla, isso já ocorre, pois somente indivíduos abstêmios por três a seis meses são habitualmente listados para transplante hepático. Pode se estar utilizando a aplicação do princípio de "dar a cada um conforme a sua posição social”, uma fórmula aristocrática de justiça, também altamente discutível, pois, como há concomitância do sistema público e privado, os doentes atendidos pelo sistema suplementar têm mais facilidade em manter seus dados clínico-laboratoriais atualizados, além de maior facilidade em se manter próximo às equipes transplantadoras, especialmente no pré e possivelmente no pós-transplante.

A aplicação pontual do princípio da necessidade pode comprometer a efetividade da iniciativa por não alterar as estruturas básicas geradoras de desigualdades. As dificuldades detectadas fora do Brasil têm ressuscitado a discussão teórica sobre a adoção de um critério para a alocação dos fígados que também considere a sobrevida obtida com o transplante ${ }^{10}$. As consequências inesperadas da utilização do MELD podem se dever mais a uma incompreensão do processo como um todo do que a um fracasso da teoria da justiça de Rawls frente à visão utilitarista.

Ao se introduzir mudanças, devem ser levadas, em conta, as forças que atuam sobre a nossa sociedade favorecendo as desigualdades e que podem ser insensíveis a alterações pontuais. Provavelmente, antes de decretar um fracasso da teoria da justiça conforme Rawls e adotar uma posição utilitarista, deva-se considerar que o sistema não atende o requisito básico de tratar os desiguais de forma desigual com o objetivo de promover equidade. A utilização de escores filosoficamente utilitaristas fere os princípios adotados pelo nosso sistema de saúde, baseado na universalidade e na equidade. $\mathrm{Na}$ verdade, o nosso viés é ainda não praticar a equidade e a universalidade, pois a distribuição desigual da captação de órgãos e do acesso a equipes transplantadoras de fígado trata os desiguais de forma igual, ou pior, trata os desiguais de forma desigual, mas não promovendo a equidade. Provavelmente, o sistema precisa praticar ainda mais o princípio da diferença, criando incentivos especiais para melhorar o desempenho na captação de órgãos (especialmente onde existem equipes transplantadoras atuantes), estimulando a criação de novas equipes transplantadoras em estados onde elas são necessárias e 
desenvolvendo bancos de dados que nos permitam compreender o fenômeno do descarte de órgãos no nosso meio. Em relação ao MELD, o acesso aos exames que garantam a atualização do escore deve ser disponibilizado independentemente da atuação das equipes. Obviamente, ainda fica a critério das equipes inativar algum doente da lista por falta de condições clínicas de realização do procedimento. Porém, não podemos aceitar que pacientes não tenham acesso a equipes transplantadoras ou que fiquem não ativos por falta de acesso a exames laboratoriais de fácil execução, ou ainda pior, por falta de comunicação adequada entre transplantadores e usuários do sistema.

Lembrando as palavras de Rawls, citadas por Sandel 39 (p. 177), para o contexto da nossa discussão: "devemos repudiar a alegação de que, se as instituições são falhas porque as circunstâncias são injustas, essa injustiça deve ser inevitavelmente transferida para as providências humanas. Eventualmente essa reflexão é usada como uma desculpa para que se ignore a injustiça, como se a recusa em aceitar a injustiça fosse o mesmo que ser incapaz de aceitar a morte".

\section{Considerações finais}

Será que o exercício propriamente dito de definir critérios para alocação de órgãos pode ser feito sob um "véu de ignorância" para as desigualdades inter e intrarregionais do país? Pode a justiça ser "cega" a essas questões como a representação da deusa romana Justitia com sua venda sobre os olhos? Quando se estabelecem e quando se aplicam as "regras do jogo", é razoável a escolha de um sistema que priorize os doentes que mais necessitem. Essa suposição se baseia no princípio maximin de decisão racional. Porém, a introdução do MELD mostrou o efeito paradoxal de instituir medidas justas em um sistema globalmente injusto. O estabelecimento dessas regras, baseadas na teoria de Rawls, deve atingir a assistência à saúde como um todo, pois a saúde pertence à "estrutura básica" da sociedade, foco central da teoria de justiça de Rawls.

Portanto, se por um lado, em um sistema de saúde que busca universalidade e equidade, privilegia como padrão a necessidade, por outro lado, a alocação de fígados para transplante pode estar privilegiando inadvertidamente outros padrões de justiça, como mérito e posição social. A concomitância de remuneração pelo sistema único de saúde e pelo sistema de saúde suplementar/privado também é um estímulo a uma visão de justiça não baseada em padrões, porém alicerçada apenas na legalidade do processo. Esse último aspecto ora oscila o pêndulo da justiça para a utilização de padrões, não necessariamente a necessidade, ora oscila o pêndulo da justiça para a ausência de padrões. Dessa forma, a alocação de fígados para transplante baseada na necessidade, definida pelo MELD, pode ter frustrado a promessa de justiça.

Finalmente, é necessário considerar que a questão envolvendo o processo de doação e transplantes é tão complexa que, embora a adoção de um escore como o MELD vise a atender a maior necessidade, também possui um caráter utilitarista intrínseco, pois reflete uma solução para a discrepância entre demanda e oferta de órgãos. Mesmo que seja possível, embora improvável harmonizar necessidade e utilidade, antes precisamos ampliar, ainda mais, a justiça distributiva de inspiração rawlsiana no Brasil. 


\section{Colaboradores}

E. M. Rodrigues-Filho idealizou o presente artigo, participando da sua escrita e ajustes finais. C. A. Franke e J. R. Junges participaram da escrita do artigo e aprovaram a versão final.

\section{Agradecimentos}

Os autores agradecem ao Programa de Pós-graduação em Saúde Coletiva da UNISINOS.

\section{Referências}

1. Rawls J. Uma teoria da justiça. 2a Ed. São Paulo: Editora Martins Fontes; 2002.

2. Mulgan T. Utilitarismo. Petrópolis: Editora Vozes; 2007.

3. De Sandro S, Ferla F, Lauterio A, Mangoni I, De Carlis R, Buscemi V, et al. The European policy for liver allocation in patients affected by hepatocellular carcinoma. Chirurgia $(\mathrm{Bu}-$ cur) 2017; 112:208-16.

4. Fleischacker S. Uma breve história da justiça distributiva. São Paulo: Editora Martins Fontes; 2006.

5. Kymlicka W. Filosofia política contemporânea. São Paulo: Editora Martins Fontes; 2006.

6. Neri D. Filosofia moral. Manual introdutivo. São Paulo: Edições Loyola; 1999.

7. Arruda Jr. EL. Direito, Marxismo e Liberalismo: ensaios para uma Sociologia crítica do Direito. Florianópolis: Editora Cesusc; 2001.

8. Smith P. Filosofia moral e política. Liberdade, direitos, igualdade e justiça social. São Paulo: Editora Madras; 2009.

9. Wolff J. Introdução à filosofia política. Lisboa: Editora Gradiva; 1996

10. Schaubel DE, Guidinger MK, Biggins SW, Kalbfleisch JD, Pomfret EA, Sharma P, et al. Survival benefit-based deceased-donor liver allocation. Am J Transplant 2009; 9(4 Pt 2):970-81.

11. Bobbert M, Ganten TM. Liver allocation: urgency of need or prospect of success? Ethical considerations. Clin Transplant 2013; 27 Suppl 25:34-9.

12. Everson GV, Trotter JF. Transplantation of the liver. In: Schiff ER, Sorrell MF, Maddrey WC, editors. Diseases of the liver. 9th Ed. Philadelphia: Lippincott Williams \& Wilkins; 2002. p. 1585-614.

13. Bismuth $\mathrm{H}$. The need for a consensus agreement on indication of liver transplantation. Hepatology 1994; 20(1 Pt 2):1S-2S.

14. Trotter JF. Liver transplantation around the world. Curr Opin Organ Transplant 2017; 22:123-7.

15. Aguirre-Valadez J, Torre A, Vilatobá M, Contreras A, Sánchez-Cedillo A, Antolinez-Motta J, et al. Indications for liver transplant. Rev Invest Clin 2014; 66:534-46.

16. Trotter JF, Osgood MJ. MELD scores of liver transplant recipients according to size of waiting list: impact of organ allocation and patient outcomes. JAMA 2004; 291:1871-4.

17. Coombes JM, Trotter JF. Development of the Allocation System for Deceased Donor Liver Transplantation. Clin Med Res 2005; 3:87-92.

18. Parent B, Caplan AL. Fair is fair: we must reallocate livers for transplant. BMC Medical Ethics 2017; 18:26.

19. Deshpande R, Hirose R, Mulligan D. Liver allocation and distribution: time for a change. Curr Opin Organ Transplant 2017; 22:162-8.

20. Kamath PS, Wiesner RH, Malinchoc M, Kremers W, Therneau TM, Kosberg CL, et al. A model to predict survival in patients with endstage liver disease. Hepatology 2001;33:464-70. 
21. Dutkowski P, Oberkofler CE, Slankamenac K, Puhan MA, Schadde E, Mullhaupt B, et al. Are there better guidelines for allocation in liver transplantation? A novel score targeting justice and utility in the model for end-stage liver disease era. Ann Surg 2011; 254:745-53.

22. Associação Brasileira de Transplantes de Órgãos. Registro Brasileiro de Transplantes 2016. http://www.abto.org.br/abtov03/Upload/file/ RBT/2016/ (acessado em 10/Jul/2017).

23. Ministério da Saúde. Portaria no 2.600, de 21 de outubro de 2009. Aprova o Regulamento Técnico do Sistema Nacional de Transplantes. Diário Oficial da União 2009; 30 out.

24. Ministério da Saúde. Portaria no 1.160, de 29 de maio de 2006. Modifica os critérios de distribuição de fígado de doadores cadáveres para transplante, implantando o critério de gravidade de estado clínico do paciente. Diário Oficial da União 2006; 31 mai.

25. Teixeira AC, Souza FF, Mota GA, Martinelli ALC, Sankarankutty AK, Castro e Silva O. Liver transplantation. Expectation with MELD score for liver allocation in Brazil. Acta Cir Bras 2006; 21 Suppl 1:12-4.

26. Ferraz-Neto B-H. MELD score, step forward to justice of liver graft allocation in Brazil. Arq Gastroenterol 2007; 44:187-8.

27. Soriano A, Varona A, Gianchandani R, Moneva ME, Arranz J, Gonzalez A, et al. Selection of patients with hepatocellular carcinoma for liver transplantation: past and future. World J Hepatol 2016; 8:58-68.

28. Brandão A, Fuchs SC, Gleisner AL, Marroni C, Zanotelli ML, Cantisani G. Model for the end-stage liver disease and death prediction in a cohort of Brazilian patients on the waiting list for liver transplantation. Clin Transplant 2008: 22:651-6.

29. Monteiro F, Coria SA, Boni R, Pereira LA Model for end-stage liver disease: impact of the new deceased donor liver allocation policy in São Paulo, Brazil. Transplant Proc 2009; 41:226-6.

30. Tenório AL, Macedo FIB, Miranda LEC, Fernandes JL, Da Silva CM, Neto OLF, et al. Survival on waiting list for liver transplantation before and after introduction of the model for end-stage liver disease score. Transplant Proc 2010; 42:407-11.
31. Batista TP, Sabat BD, Melo PSV, Miranda LEC, Neto OLF, Amorim AG, et al. Impact of MELD allocation policy on survival outcomes after liver transplantation: a single-center study in northeast Brazil. Clinics 2011; 66:57-64.

32. Salvalaggio PR, Afonso RC, Pereira LA, FerrazNeto BH. Testing liver allocation in São Paulo, Brazil: the relationship of model for end-stage liver disease implementation with a reduction in waiting-list mortality. Transplant Proc 2012; 44:2283-5.

33. Machado AGS, Fleck Jr AM, Marroni C, Zanotelli ML, Cantisani G, Brandão ABM. Impact of MELD score implementation on liver allocation: experience at a Brazilian center. Ann Hepatol 2013; 12:440-7.

34. Pestana RC, Baracat EI, Massarollo PC, Pereira LA, Szutan LA. Consequences of the implementation of the model for end-stage liver disease system for liver allocation in Brazil. Transplant Proc 2013; 45:2111-4.

35. Mattos AZ, Mattos AA, Sacco FKF, Hoppe L, Oliveira DMS. Analysis of the survival of cirrhotic patients enlisted for liver transplantation in the pre-and post-MELD era in Southern Brazil. Arq Gastroenterol 2014; 51:46-52.

36. Fortes PAC. Orientações bioéticas de justiça distributiva aplicada às ações e aos sistemas de saúde. Rev Bioét 2008; 16:25-39.

37. Friesen P. Personal responsibility within health policy: unethical and ineffective. J Med Ethics 2018; 44:53-8.

38. Albertsen A. Drinking in the last chance saloon: luck egalitarianism, alcohol consumption, and the organ transplant waiting list. Med Health Care Philos 2016; 19:325-38.

39. Sandel MJ. Justiça. O que é fazer a coisa certa. Rio de Janeiro: Editora Civilização Brasileira; 2009. 


\section{Abstract}

The process of liver donations and transplants in Brazil reveals major inequalities between regions and states of the country, ranging from uptake of the organs to their transplantation. In 2006, the $M E L D$ score (Model for End-stage Liver Disease), inspired by the U.S. model and based on the principle of need, was introduced in Brazil for liver transplant allocation. However, Brazil's inequalities have partially undermined the initiative's success. Other countries have already benefited from growing discussion on the benefits of models that seek to harmonize utilitarianism and need. The current article reviews the relevant literature with a special focus on the Brazilian reality.

Liver Transplantation; Tissue and Organ Procurement; Health Policy

\section{Resumen}

El proceso de donación y trasplante hepático en Brasil revela grandes desigualdades entre regiones y unidades de la federación, desde la captación del órgano hasta el implante del mismo. En 2006, el marcador MELD (Model for End-stage Liver Disease), inspirado en el modelo estadounidense, $y$ basado en el principio de necesidad, fue incorporado en Brasil para la asignación en trasplantes de hígado. No obstante, las desigualdades en nuestro país han comprometido, parcialmente, el éxito de esta iniciativa. En otros países, ya se vive una creciente discusión sobre el beneficio de modelos que intentan armonizar utilitarismo y necesidad. Este artículo revisa la literatura pertinente, centrándose especialmente en la realidad brasileña.

Trasplante de Hígado; Obtención de Tejidos y Órganos; Política de Salud 
